\title{
Ferrugem em Plumeria spp. (Apocynaceae) em Mato Grosso do Sul ${ }^{(1)}$
}

\author{
CASSIA DE CARVALHO(2), CAMILA SOARES ROSA LEMES(2), JOSÉ CARLOS SORGATO(2), \\ WALBER LUIZ GAVASSONI(2), LILIAN MARIAARRUDA BACCHI(2), LUCIA MAYUMI HIRATA(2)
}

\begin{abstract}
RESUMO
O jasmim-manga (Plumeria spp.) é uma planta muito utilizada na ornamentação urbana, principalmente por sua rusticidade, fácil manejo e exuberância de suas flores. Folhas de Plumeria spp. foram coletadas no município de Dourados, MS, com sintomas e sinais típicos da presença de ferrugem: uredinias pulverulentas de coloração amarelada na face abaxial e manchas cloróticas e necróticas, na face adaxial das folhas, culminando algumas vezes com abscisão foliar. O presente trabalho tem por objetivo registrar a ocorrência da doença no Estado de Mato Grosso do Sul. Observações microscópicas e mensurações de urediniosporos e teliosporos confirmaram a presença do fungo Coleosporium plumeriae infectando essas plantas.
\end{abstract}

Palavras-chave: Coleosporium plumeriae, jasmim-manga.

\begin{abstract}
Rust in Plumeria spp. (Apocynaceae) in the State of Mato Grosso do Sul, Brazil.

Frangipani (Plumeria spp.) is a plant widely used in urban ornamentation, due to its hardiness, easy handling and exuberance of its flowers. Plumeria spp. Leaves were collected in Dourados, MS, Brazil, with typical symptoms and signs of the presence of rust: powdery yellowish uredinias in the abaxial and chlorotic and necrotic spots on the adaxial surface of the leaves, sometimes resulting in leaf abscission. The present study aims to record the occurrence of the disease in the State of Mato Grosso do Sul. Microscopic observations and measurements of uredinospores and teliospores confirmed that the fungus infecting plants was Coleosporium plumeriae.
\end{abstract}

Keywords: Coleosporium plumeriae, Frangipani.

Plumeria (Plumeria spp.), mais conhecida como jasmimmanga é uma planta originária da América tropical, muito utilizada para ornamentar parques, praças e jardins (LORENZI e MOREIRA, 2008). As espécies e híbridos variam quanto ao porte da árvore, compacidade, ramificação, formato da folha, deciduidade, tamanho e cor das flores. As folhas são geralmente verde brilhantes, comumente ovaladas, variando de 5 a $10 \mathrm{~cm}$ de largura e 20 a $30 \mathrm{~cm}$ de comprimento. As flores são tubulares, ampliando em um "cata-vento" de cinco pétalas com 5 a $7 \mathrm{~cm}$ de diâmetro, podendo ser branca, vermelha, amarela, rosa ou cores variadas (Figura 1A) (CRILEY, 2005).

Há poucos relatos da ocorrência de doenças associadas à Plumeria spp., no entanto, o fungo Coleosporium plumeriae Patoillard é relatado causando ferrugem em plantas desse gênero em vários países. A ferrugem do jasmim-manga foi registrada pela primeira vez em Plumeria alba na ilha de Guadalupe em 1902 e mais tarde disseminou-se para a América Central (NELSON, 2009). No Brasil, a doença já foi identificada nos Estados do Amapá, Amazonas, Bahia, Ceará, Maranhão, Minas Gerais, Pernambuco, Piauí, Rio de Janeiro e São Paulo (HENNEN et al., 2005; FREIRE e MOSCA, 2009).

No mês de janeiro de 2012, foram encontradas plantas de Plumeria spp. apresentando sintomas de ferrugem em folhas de mudas e plantas adultas, de diferentes idades em Dourados/ MS/Brasil. Posteriormente foi confirmada sua ocorrência nos municípios de Campo Grande, Naviraí, Paranaíba e Ponta Porã.

Folhas com sintomas foram coletadas e levadas ao
Laboratório de Fitopatologia e Microbiologia Agrícola da Universidade Federal da Grande Dourados, objetivando a identificação do patógeno.

Em microscópio estereoscópico, as folhas foram observadas e, após realizados cortes transversais dos tecidos foliares, foram confeccionadas lâminas semipermanentes utilizando corante azul-algodão. Em seguida, as lâminas foram observadas em microscópio óptico.

A face adaxial das folhas apresentavam manchas amareladas (Figura 1B), que com o decorrer do tempo tornavam-se necróticas, culminando na abscisão foliar (Figura 1D). Na superfície abaxial foram encontradas uredinias pulverulentas de coloração amarelo-alaranjado e com intensa produção de urediniosporos (Figuras 1C e E-1). Estes, quando observados microscopicamente, apresentaram-se catenulados, verrucosos, equinulados, unicelulares, não pedicelados, de parede externa espessa e não pigmentada, apresentando dimensões de 27,8 a 35,6 $\mu \mathrm{m}$ x 19,6 a 24,4 $\mu \mathrm{m}$.

Também observou-se télias subepidérmicas de coloração vermelho-alaranjado (Figura 1E-2), contendo teliosporos com dimensões variando de 53,1 a 98,3 $\mu \mathrm{m}$ x 15,1 a 20,5 $\mu \mathrm{m}$ (Figuras $1 \mathrm{~F}$ e $1 \mathrm{G}$ ). De acordo com o Bulletin de la Société Mycologique de France (PATOUILLARD, 1902) e o Catalogue of the species of plant rust fungi (Uredinales) of Brazil (HENNEN et al., 2005), as características observadas correspondem ao fungo Coleosporium plumeriae Patouillard, sendo este o primeiro relato da ocorrência de Coleosporium plumeriae em Plumeria spp. no Estado de Mato Grosso do Sul.

\footnotetext{
(1) Trabalho recebido para publicação em 26/03/2013 e aprovado em 26/05/2014

(2) Faculdade de Ciências Agrárias/UFGD campus II, Rodovia Dourados - Itahum, km 12, CEP 79.804-070. Email correspondência: cassia_pgagro@hotmail.com
} 


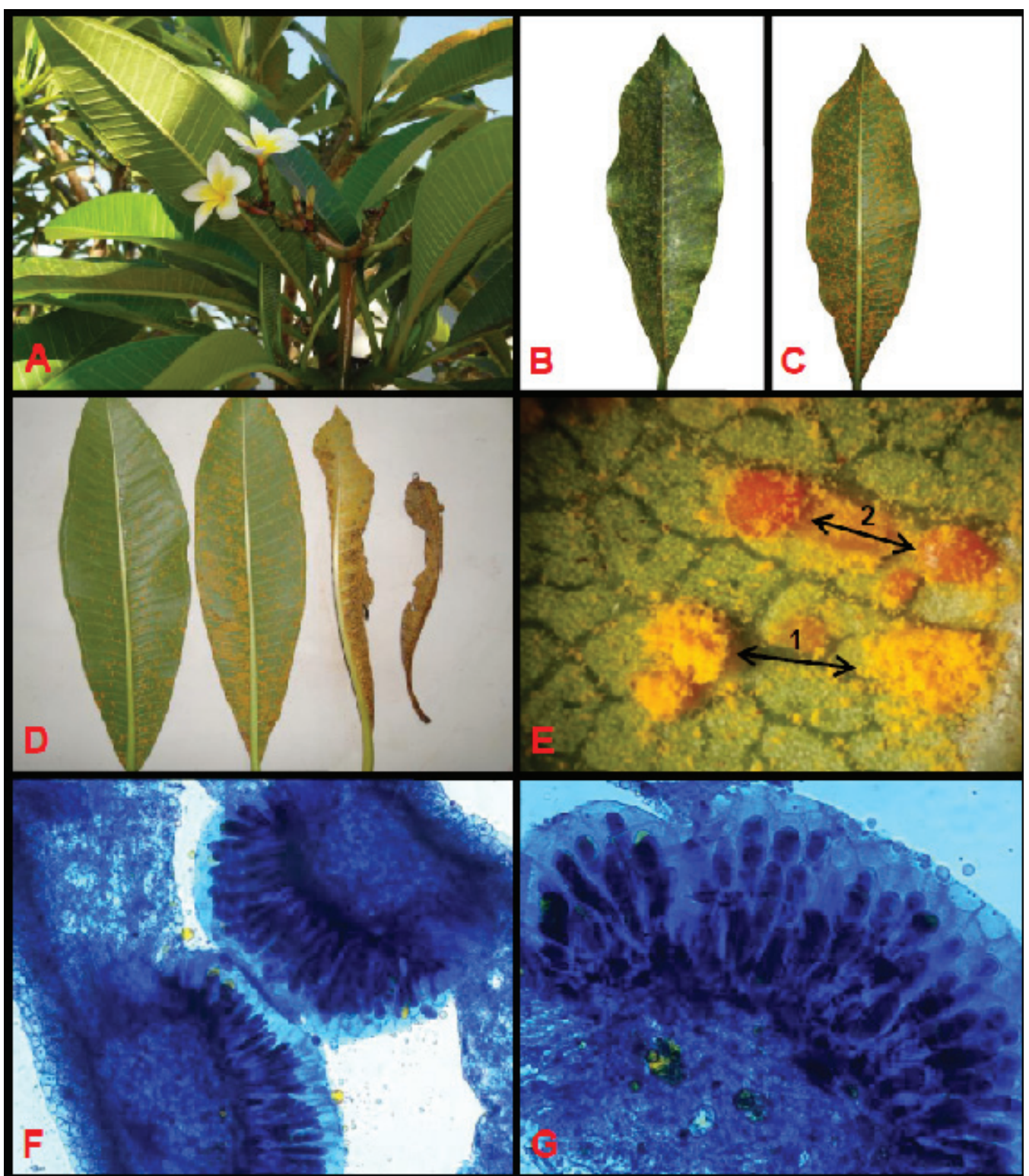

Figura 1. Coleosporium plumeriae em Plumeria spp.: (A) aspecto das folhas e flores de Plumeria spp.; (B) sintomas na face adaxial e (C) abaxial da folha; (D) folhas com diferentes níveis de severidade; (E1) uredinias; (E2) télias subepidérmicas; (F) corte transversal do tecido foliar com télias em aumento de 100x; (G) teliosporos em corte transversal em aumento de 400x.

Figure 1. Coleosporium plumeriae in Plumeria spp.: (A) aspect of the leaves and flowers of Plumeria spp.; (B) symptoms on the adaxial and (C) abaxial leaf; (D) leaves with different severity levels; (E1) uredinias; (E2) telias subepidermal; $(F)$ cross-section of leaf tissue with telias at 100x magnification; $(G)$ teliospores cross-sectional 400x magnification.

\section{REFERÊNCIAS}

CRILEY, R.A. Plumeria in Hawai'i. Disponível em: <http:// www.ctahr.hawaii.edu/ oc/freepubs/pdf/OF-31.pdf> Acesso em: 06/08/2012.

FREIRE, F.C.O; MOSCA, J.L. Patógenos associados a doenças de plantas ornamentais no Estado do Ceará. Revista Brasileira de Horticultura Ornamental, Campinas, v.15, n.1, p.83-89, 2009.

HENNEN, J. F.; FIGUEIREDO, M. B.; CARVALHO JUNIOR, A.A.; HENNEN, P.G. Catalogue of the species of plant rust fungi (Uredinales) of Brazil. Disponível em: <http://www. jbrj.gov.br/publica/livros_pdf/catalogue.pdf> Acesso em: $01 / 05 / 2012$.

LORENZI, H., MOREIRA, S.H. Plantas ornamentais no Brasil: arbustivas, herbáceas e trepadeiras. 4.ed. Nova Odessa: Instituto Plantarum, 2008. 1088p.

NELSON, S. Plumeria Rust. Disponível em: <http://www. ctahr.hawaii.edu/oc/ freepubs/pdf/PD-61.pdf $>$ Acesso em: 02/05/2012.

PATOUILLARD, N. Coleosporium Lév. Bulletin de la Société Mycologique de France. Paris, v. 18, p.178, 1902. 